\title{
STUDI PENGARUH MATERIAL GEOSINTETIK DALAM DISTRIBUSI BEBAN KERJA PADA KONSTRUKSI JALAN DI ATAS TANAH LUNAK
}

\author{
Sastrawinata $^{1}$ dan Andryan Suhendra ${ }^{2}$ \\ ${ }^{1}$ Program Studi Sarjana Teknik Sipil, Universitas Tarumanagara, Jl. Letjen S. Parman No.1 Jakarta \\ Sastrawinata.325150173@stu.untar.ac.id \\ ${ }^{2}$ Program Studi Sarjana Teknik Sipil, Universitas Tarumanagara, Jl. Letjen S. Parman No.1 Jakarta \\ andryansuhendra@yahoo.com
}

Masuk: 17-01-2020, revisi: 14-02-2020, diterima untuk diterbitkan: 15-02-2020

\begin{abstract}
Soft soil is commonly become the main problem in various types of construction processes. It causes a very big load distribution in soils that will affect the construction process that will take place. Soft soils have a low bearing capacity which can result in loss, costs that become more expensive to construction safety, that is, structures that are made unable to stand stable and are not sturdy. This can be prevented by stabilizing soft soils using geotextile reinforcement. Geotextile material works using membrane effect method which only relies on its own tensile strength which can help to reduce the load distribution that occur on sof soils. In one of the road projects in Jakarta, road will be made with very soft soil subgrade. To reduce the load distribution, embankment is carried out on existing land with geotextile reinforcement in between. This geotextile material is proven to reduce the load distribution that occurs in soft soils so the value of the load distribution will be smaller. For more effective use, the geotextile used in this project must be placed at 0,2 metres height above the subgrade.
\end{abstract}

Keywords: point load; load distribution; geotextile; soft soil; SPT; embankment

\begin{abstract}
ABSTRAK
Tanah lunak seringkali menjadi sumber masalah yang paling banyak terjadi pada berbagai jenis proses kontruksi. Tanah ini menyebabkan distribusi beban yang terjadi sangatlah besar sehingga akan berpengaruh terhadap proses konstruksi yang akan berlangsung. Tanah lunak mempunyai daya dukung yang sangat kecil yang dapat mengakibatkan kerugian, mulai dari kerugian biaya yang menjadi lebih mahal hingga keselamatan konstruksi, yaitu struktur yang dibuat tidak mampu berdiri stabil dan tidak kokoh. Hal ini dapat dicegah dengan menstabilisasi tanah lunak dengan menggunakan perkuatan geotekstil. Material geotekstil bekerja menggunakan metode membrane effect yang hanya mengandalkan kuat tariknya sendiri yang dapat membantu mengurangi distribusi beban yang terjadi pada tanah lunak. Pada salah satu proyek jalan di Jakarta, akan dibuat jalan dengan tanah dasar tanah yang sangat lunak. Untuk membantu dalam mengurangi distribusi beban yang terjadi, dilakukan penimbunan tanah di atas tanah eksisting dengan perkuatan geotekstil di antaranya. Material geotekstil ini terbukti dapat mengurangi distribusi beban yang terjadi pada tanah lunak sehingga nilai distribusi beban yang terjadi menjadi lebih kecil. Untuk penggunaan yang lebih efektif, letak geotekstil yang digunakan pada proyek ini harus diletakkan pada ketinggian 0,2 meter di atas tanah dasar.
\end{abstract}

Kata kunci: beban titik; distribusi beban; geotekstil; tanah lunak; SPT; timbunan

\section{PENDAHULUAN}

\section{Latar belakang}

Tanah lunak mempunyai daya dukung yang sangat kecil yang dapat mengakibatkan kerugian, mulai dari kerugian biaya yang menjadi lebih mahal hingga keselamatan konstruksi, yaitu struktur yang dibuat tidak mampu berdiri stabil dan tidak kokoh.

Oleh karena itu, tanah lunak harus distabilisasi terlebih dahulu. Penstabilisasian tanah lunak dapat dilakukan dengan menggunakan berbagai macam metode perbaikan tanah, salah satunya adalah dengan menggunakan material geosintetik untuk mengurangi distribusi beban yang terjadi. 
Objek yang digunakan dalam penelitian ini adalah timbunan setinggi $50 \mathrm{~cm}$, analisis hitungan dilakukan dengan menggunakan program berbasis metode elemen hingga, metode distribusi tegangan beban menggunakan distribusi tegangan beban titik, tanah yang ditinjau merupakan Unpaved Road, jenis perkuatan tanah yang digunakan adalah material geosintetik berupa geotekstil, dan tidak memperhitungkan pencampuran material baru dengan tanah dasar.

Dalam penelitian ini akan dibahas mengenai distribusi beban tanpa perkuatan tanah, distribusi beban dengan menggunakan perkuatan tanah geotekstil, menganalisa efektivitas penggunaan geotekstil, yang bertujuan untuk membandingkan distribusi beban kerja yang terjadi pada tanah lunak dengan perkuatan geosintetik dan tanpa perkuatan geosintetik.

\section{Geosintetik}

Menurut Pedoman Konstruksi dan Bangunan (2009), geosintetik memiliki enam fungsi yakni: Filtrasi: bahan geosintetik digunakan untuk mengalirkan air ke dalam sistem drainase dan mencegah terjadinya migrasi partikel tanah melalui filter. Contoh penggunaan geosintetik sebagai filter adalah pada sistem drainase porous, Drainase: bahan geosintetik digunakan untuk mengalirkan air dari dalam tanah. Bahan ini contohnya digunakan sebagai drainase di belakang abutmen atau dinding penahan tanah, Separator: bahan geosintetik digunakan di antara dua material tanah yang tidak sejenis untuk mencegah terjadi pencampuran material. Sebagai contoh, bahan ini digunakan untuk mencegah bercampurnya lapis pondasi jalan dengan tanah dasar yang lunak sehingga integritas dan tebal rencana struktur jalan dapat dipertahankan, Perkuatan: sifat tarik bahan geosintetik dimanfaatkan untuk menahan tegangan atau deformasi pada struktur tanah, Penghalang: bahan geosintetik digunakan untuk mencegah perpindahan zat cair atau gas. Fungsi geosintetik ini contohnya adalah geomembran untuk menjaga fluktuasi kadar air pada tanah ekspansif atau digunakan pada penampungan sampah, Proteksi: bahan geosintetik digunakan sebagai lapisan yang memperkecil tegangan lokal untuk mencegah atau mengurangi kerusakan pada permukaan atau lapisan tersebut. Sebagai contoh, tikar geotekstil (mat) digunakan untuk mencegah erosi tanah akibat hujan dan aliran air. Contoh lainnya, geotekstil tak-teranyam digunakan untuk mencegah tertusuknya geomembran oleh tanah atau batu di sekelilingnya pada saat pemasangan.

\section{Geotekstil}

Menurut ASTM D4439, pengertian geosintetik adalah sebuah produk planar yang dibuat dari material polimer yang digunakan pada tanah, batuan, bumi atau rekayasa geoteknik lainnya yang berhubungan dengan material sebagai salah satu bagian dari man-made project, struktur, atau sistem. Material yang digunakan untuk pembuatan geosintetik umumnya dihasilkan oleh industri plastik seperti polimer, karet, fiber-glass, dan material alam yang terkadang dipakai.

Geotekstil secara garis besar dibedakan menjadi dua jenis yaitu geotekstil woven dan geotekstil non-woven. Kedua jenis material geotekstil tersebut dibedakan pada cara pembuatannya. Geotekstil woven dibuat dengan cara dianyam sedangkan geotekstil non-woven tidak dianyam, sehingga tekstur dari geotekstil woven terlihat lebih teratur dibandingkan dengan geotekstil non-woven.

Perbedaan jenis dan bentuk dari geotekstil ini menjadikan setiap geotekstil mempunyai kelebihan dan kekurangannya masing-masing. Umumnya, geotekstil woven digunakan sebagai perkuatan tanah dasar karena tekstur dari geotekstil yang teranyam rapi sehingga mempunyai kuat tarik (tensile strength) yang lebih besar dibandingkan dengan geotekstil non-woven.

\section{Timbunan}

Pekerjaan ini termasuk dalam pengadaan, pengangkutan, penghamparan, dan pemadatan tanah atau bahan berbutir halus yang disetujui untuk timbunan. yang diperlukan untuk membentuk dimensi timbunan sesuai dengan garis, kelandaian, dan elevasi penampang melintang yang disyaratkan atau disetujui. Timbunan dapat dibagi menjadi tiga jenis yaitu timbunan biasa, timbunan pilihan dan timbunan pilihan diatas rawa.

Timbunan yang diklasifikasikan sebagai timbunan biasa harus terdiri dari bahan galian tanah atau batu yang memenuhi syarat untuk digunakan dalam pekerjaan. Timbunan pilihan dapat digunakan sebagai lapis perbaikan tanah dasar (subgrade) untuk meningkatkan daya dukung tanah dasar, juga digunakan pada saluran air, meningkatkan kestabilan lereng, maupun pekerjaan pelebaran timbunan. Timbunan pilihan digunakan diatas tanah rawa yang selalu digenangi air.

Dalam mengestimasi besar penurunan pada tanah lempung dengan konsolidasi berlebih membutuhkan perkuatan tanah sebelum konstruksi dilakukan. Hal ini akan meningkatkan biaya dan waktu konstruksi disebabkan kuat geser tanah yang rendah perlu perancangan sedemikian rupa (Vipulanandan, C., 2009). 


\section{Distribusi beban}

Menurut Budhu (2011), distribusi tegangan dalam tanah yang telah diberi beban ditentukan dengan mengasumsikan bahwa tanah bersifat semi-infinite, homogen, linear, isotropik dan elastis. Massa semi-infinite dibatasi di satu sisi dan dapat meluas tanpa batas ke semua arah lainnya, ini juga disebut "elastic halfspace".

Untuk tanah, permukaan horisontal adalah sisi yang terikat. Karena asumsi elastis linear massa tanah kita bisa menggunakan prinsip superposisi, yang artinya tegangan meningkat pada titik tertentu dalam massa tanah pada arah tertentu dari beban yang berbeda dapat ditambahkan.

Beban permukaan dibagi menjadi dua, yaitu finite dan infinite. Contoh dari beban finite adalah beban titik, beban lingkaran, dan beban persegi panjang. Contoh dari beban infinite adalah fill and surcharges.

\section{Metode distribusi tegangan dengan perkuatan}

Giroud dan Nouray menggunakan model geometrik untuk sebuah beban roda $\left(P_{e c}\right)$ dalam area B x L, yang tersebar melalui $h_{o}$, ketebalan tanah dasar tanpa geotekstil dan $h$, ketebalan tanah dasar dengan geotekstil.

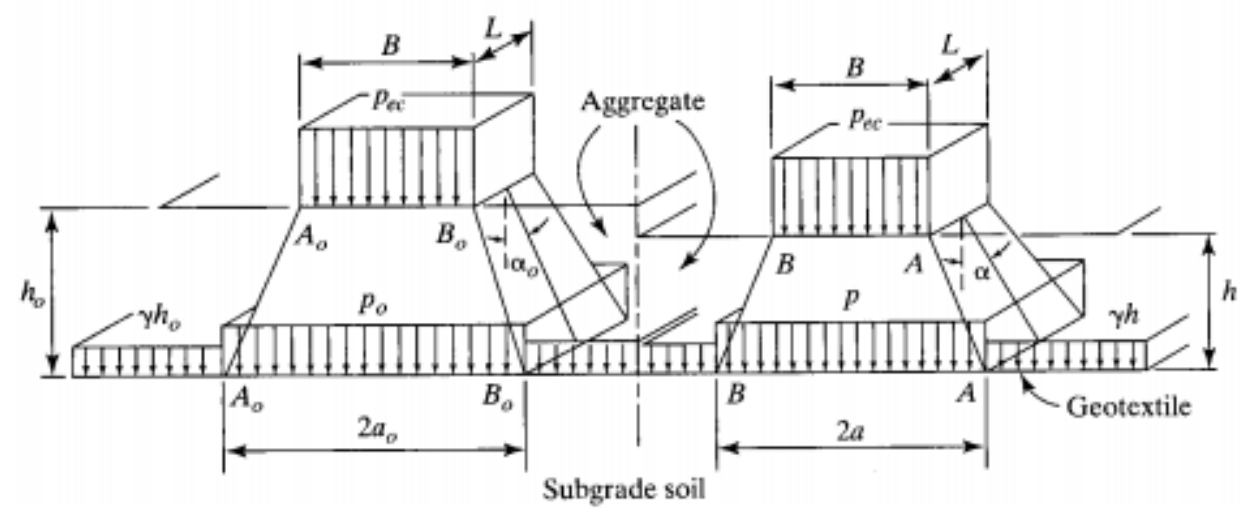

(a) Case without geotextile

(b) Case with geotextile

Gambar 1. Distribusi beban pada lapisan agregat (Sumber: Giroud dan Nouray, 1981)

Model tersebut menunjukkan hasil dari tegangan pada tanah dasar $p_{o}$ (tanpa geotekstil) dan $p$ (dengan geotekstil) sebagai berikut:

$$
\begin{gathered}
p o=\frac{P}{2(B+2 h o \tan \propto o)(L+2 h o \tan \propto o)}+\gamma h o \\
p=\frac{P}{2(B+2 h \tan \propto)(L+2 h \tan \propto)}+\gamma h
\end{gathered}
$$

dengan $\mathrm{P}=$ Beban gandar, $\gamma=$ Berat tanah.

Setelah tegangan dari beban gandar diketahui, teori fondasi dangkal dapat digunakan. Tanah yang digunakan harus dalam keadaan undrained agar kuat geser yang digunakan adalah kohesi dari tanah $(c)$. Asumsi untuk kemampuan maksimal tanah dalam menahan beban tanpa perkuatan geotekstil berdasarkan batas elastis tanah dapat menggunakan rumus sebagai berikut :

$$
p_{o}=\pi_{\mathrm{c}}+\gamma \mathrm{h}_{\mathrm{o}}
$$

Dan dengan perkuatan geotekstil, tekanan batas dapat ditingkatkan sampai daya dukung batas sebagai berikut,

$$
p^{*}=(\pi+2) \mathrm{c}+\gamma \mathrm{h}
$$

Jadi untuk kasus tanpa perkuatan geotekstil, persamaan (1) dan (3) dapat diselesaikan dengan menggunakan persamaan (5),

$$
\mathrm{c}=\frac{P}{2 \pi\left(\sqrt{\frac{P}{p c}}+2 h o \tan \alpha o\right)\left(\sqrt{\frac{P}{2 p c}}+2 h o \tan \alpha o\right)}
$$

dengan $\mathrm{c}=$ Kohesi tanah, $\mathrm{P}=$ Beban gandar, $\mathrm{p}_{\mathrm{c}}=$ Peningkatan tekanan roda, $\mathrm{h}_{\mathrm{o}}=$ Ketebalan agregat, $\alpha_{\mathrm{o}}=$ Sudut distribusi beban $\left(\sim 26^{\circ}\right)$. 
Untuk kasus dimana perkuatan geotekstil digunakkan, $p^{*}$ pada persamaan (4) dapat digantikan dengan $\left(p-p_{g}\right)$, dimana $p_{g}$ adalah fungsi dari kekakuan pada geotekstil, maka perpanjangannya sangat penting. Atas dasar kemungkinan terjadi defleksi pada sistem geotekstil,

$$
p_{g}=\frac{E \epsilon}{a \sqrt{1+\left(\frac{a}{2 S}\right)^{2}}}
$$

dengan $\mathrm{E}=$ Modulus geotekstil,$\epsilon=$ Pemanjangan, $\mathrm{a}=$ Properti geometric, $\mathrm{S}=$ Penurunan dibawah roda (bekas roda)

Dengan menggabungkan persamaan (2), (4) dan (6) dan menggunakan $p^{*}=p-p_{g}$, menghasilkan persamaan (7), dimana $h$ adalah ketebalan agregat yang belum diketahui. Ini bisa digambarkan untuk variasi tebal bekas roda dan variasi modulus geotekstil.

$$
(\pi+2) \mathrm{c}=\frac{P}{2(B+2 h \tan \propto)(L+2 h \tan \propto)}-\frac{E \epsilon}{\alpha \sqrt{1+\left(\frac{a}{2 S}\right)^{2}}}
$$

Dari dua hasil persamaan diatas, $h_{o}$ (ketebalan tanpa geotekstil) dan $h$ (ketebalan dengan geotekstil) dapat dihitung. Dari dua hasil tersebut, $\Delta h=h_{o}-h$ bisa didapatkan, yang mewakili besarnya agregat yang disimpan setelah digunakannya geotekstil.

Menurut John, N.W.M (1987), tan $\alpha$ yang digunakan untuk perhitungan adalah sebesar 0,6.

\section{Parameter B dan L}

Menurut Giroud and Nouray (1981), Parameter B dan L terbagi atas klasifikasi jenis kendaraan yang bisa dihitung dengan menggunakan rumus sebagai berikut:

Untuk kendaraan jalan raya normal termasuk truk

$$
\begin{gathered}
\mathrm{B}=\sqrt{\frac{p a}{p t}} \\
\mathrm{~L}=0,707 \mathrm{~B}
\end{gathered}
$$

Untuk kendaraan berat dengan roda lebar ganda

$$
\begin{gathered}
\mathrm{B}=\sqrt{1,414 p a / p t} \\
\mathrm{~L}=0,5 \mathrm{~B}
\end{gathered}
$$

dengan pa $=$ axle load, $\mathrm{pt}=$ tire pressure.

\section{METODE PENELITIAN}

\section{Pengumpulan data}

Kajian teknis kali ini berada di salah satu proyek di Indonesia. Data yang dikumpulkan adalah berdasarkan hasil pengamatan, pencatatan, dan uji laboratorium. sehingga data yang diperoleh sudah sesuai dengan kondisi di lapangan.

\section{Pengelolaan data}

Pada proses pengelolaan data, data-data desain yang telah dikumpulkan di lapangan diolah menggunakan program berbasis metode elemen hingga. Data desain dilapangan dimodelkan ke dalam program untuk diolah, yang kemudian dapat digunakan untuk menganalisis distribusi beban kerja akibat perkuatan geosintetik.

\section{Diagram alir}

Diagram alir untuk penelitian ini dapat dilihat pada Gambar 2. 


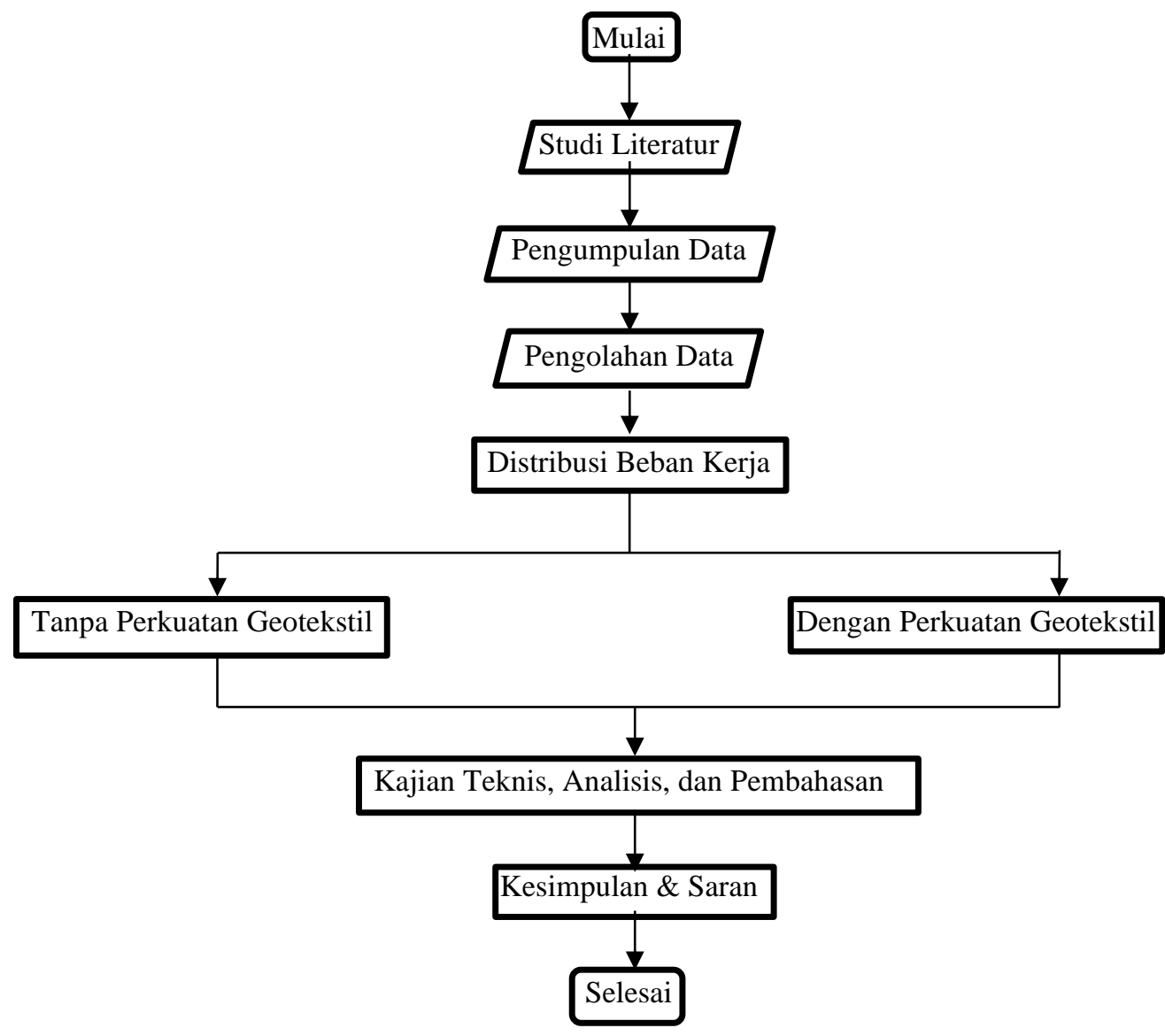

Gambar 2. Diagram alir

\section{HASIL DAN PEMBAHASAN}

\section{Parameter tanah}

Parameter tanah didapat berdasarkan hasil korelasi dari data tanah yang tersedia. Adapun ringkasan parameter tanah yang digunakan dalam penelitian ini dapat dilihat pada Tabel 1.

Tabel 1. Ringkasan parameter tanah

\begin{tabular}{cccccccc}
\hline $\begin{array}{c}\text { Depth } \\
(\mathrm{m})\end{array}$ & $\begin{array}{c}\text { Soil } \\
\text { Type }\end{array}$ & Soil Consistency & $\begin{array}{c}\gamma_{\mathrm{sat}} \\
\left(\mathrm{kN} / \mathrm{m}^{3}\right)\end{array}$ & $\begin{array}{c}\mathrm{C} \\
\left(\mathrm{kN} / \mathrm{m}^{2}\right)\end{array}$ & $\begin{array}{c}\mathrm{E} \\
\left(\mathrm{kN} / \mathrm{m}^{2}\right)\end{array}$ & $\begin{array}{c}\phi \\
\left({ }^{\circ}\right)\end{array}$ & $v$ \\
\hline $0-4$ & Gambut & Very Soft & 15,6 & 20 & 4000 & 0 & 0,35 \\
$4-11$ & $\begin{array}{c}\text { Pasir } \\
\text { Lanauan }\end{array}$ & Loose & 17,71 & 0,5 & 5873 & 25 & 0,35 \\
$11-12$ & $\begin{array}{c}\text { Pasir } \\
\text { Lanauan }\end{array}$ & Medium Dense & 18,63 & 0,5 & 15320 & 29 & 0,30 \\
& & & & & & & \\
$12-20$ & Lanau \\
& Pasiran & Stiff & 17,02 & 50 & 10000 & 30 & 0,30 \\
\hline
\end{tabular}




\section{Material geotekstil}

Material Geosintetik yang digunakan berupa geotekstil. Geotekstil yang digunakan mempunyai spesifikasi sebagai berikut:

- $\quad$ Characteristic Initial Strength $(\mathrm{T})(\mathrm{kN} / \mathrm{m})=200$

- $\quad$ Strain at initial strength $(\%)=10$

- $\quad$ Modulus Elastisitas $(\mathrm{kN} / \mathrm{m})=2000$

\section{Pemodelan pada program berbasis metode elemen hingga}

Pemodelan untuk perhitungan distribusi beban kerja dapat dilihat pada Gambar 3.

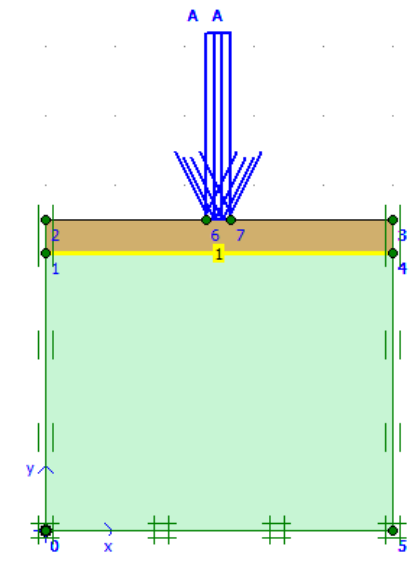

Gambar 3. Pemodelan kedalaman 4 meter

Lapisan pertama merupakan lapisan timbunan tanah dengan kedalaman 0,5 meter, lapisan kedua merupakan lapisan tanah gambut dengan kedalaman 4 meter.

Beban teori yang digunakan adalah sebesar $80 \mathrm{kN}$, sedangkan untuk pemodelan karena digunakan beban merata, maka beban $80 \mathrm{kN}$ dibagi dengan luas $\mathrm{B}$, sedangkan L dianggap infinite jadi diasumsikan 1, sehingga beban yang digunakan adalah sebesar $228,5714 \mathrm{kN} / \mathrm{m}$.

\section{Distribusi beban secara teori}

Persamaan yang diajukan oleh Giroud dan Nouray untuk perhitungan distribusi beban yang terjadi pada tanah tanpa dan dengan perkuatan geotekstil dapat dilihat pada persamaan (1) dan (2).

- Tanpa perkuatan geotekstil

$$
\begin{aligned}
& \text { po }=\frac{P}{2(B+2 h o \tan \propto 0)(L+2 h o \tan \propto 0)}+\gamma h o \\
& p o=\frac{80 k N}{2(0,35 m+2 * 0,5 * \tan 26)(1 m+2 * 0,5 * \tan 26)}+16 * 0,5 \\
& p o=40,0944 \mathrm{kN} / \mathrm{m}^{2}
\end{aligned}
$$

- Dengan perkuatan geotekstil

$$
\begin{aligned}
& p=\frac{P}{2(B+2 h \tan \propto)(L+2 h \tan \propto)}+\gamma h \\
& p=\frac{80 k N}{2(0,35 m+2 * 0,5 * 0,6)(1 m+2 * 0,5 * 0,6)}+16 * 0,5 \\
& p=34,3158 \mathrm{kN} / \mathrm{m}^{2}
\end{aligned}
$$

\section{Distribusi beban dengan metode elemen hingga}

Berikut ini adalah hasil yang didapatkan dari program berbasis metode elemen hingga untuk perhitungan distribusi beban yang terjadi pada tanah dengan dan tanpa perkuatan geotekstil.

A. Tanpa Perkuatan Geotekstil 
Pada Gambar 4, dapat dilihat persebaran distribusi tegangan yang terjadi pada tanah tanpa perkuatan geotekstil.

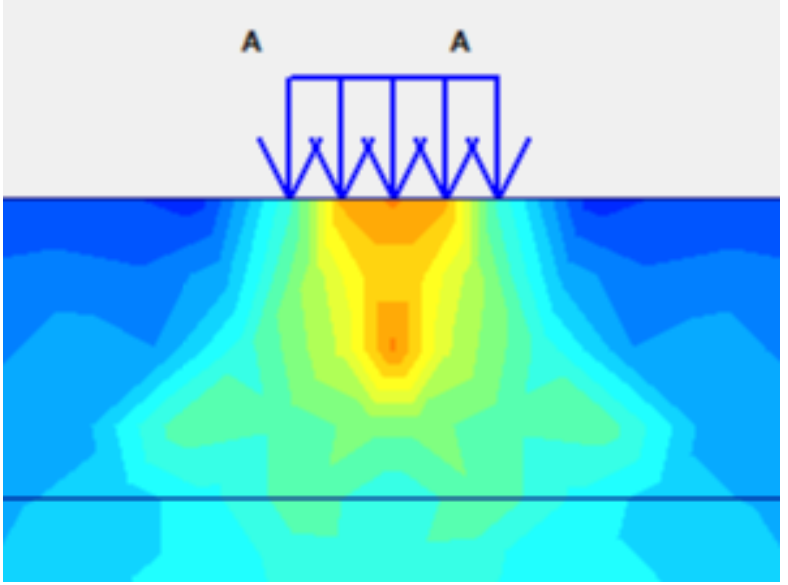

Gambar 4. Distribusi tegangan tanpa perkuatan geotekstil

Besarnya distribusi tegangan yang terjadi pada tanah tanpa perkuatan geotekstil terbagi menjadi beberapa data. Data tersebut dapat dilihat pada Tabel 2.

Tabel 2. Nilai distribusi tegangan tanpa perkuatan geotekstil

\begin{tabular}{cc}
\hline $\mathrm{X}(\mathrm{m})$ & $\begin{array}{c}p \\
\left(\mathrm{kN} / \mathrm{m}^{2}\right)\end{array}$ \\
\hline 1,88 & $-13,91$ \\
2,00 & $-15,35$ \\
2,13 & $-16,96$ \\
2,25 & $-20,33$ \\
2,37 & $-25,61$ \\
2,50 & $-31,56$ \\
2,50 & $-39,42$ \\
\hline
\end{tabular}

Pada Tabel 2 nilai terbesar untuk distribusi tegangan adalah sebesar $-39,42 \mathrm{kN} / \mathrm{m}^{2}$. Persen perbandingan untuk perbandingan besarnya nilai teori dan program adalah sebagai berikut:

$$
\begin{aligned}
\% \text { perbandingan } & =\frac{40,0944-39,42}{40,0944} * 100 \\
& =1,682 \%
\end{aligned}
$$

\section{B. Dengan Perkuatan Geotekstil}

Pada Gambar 5, dapat dilihat persebaran distribusi tegangan yang terjadi pada tanah dengan perkuatan geotekstil. 


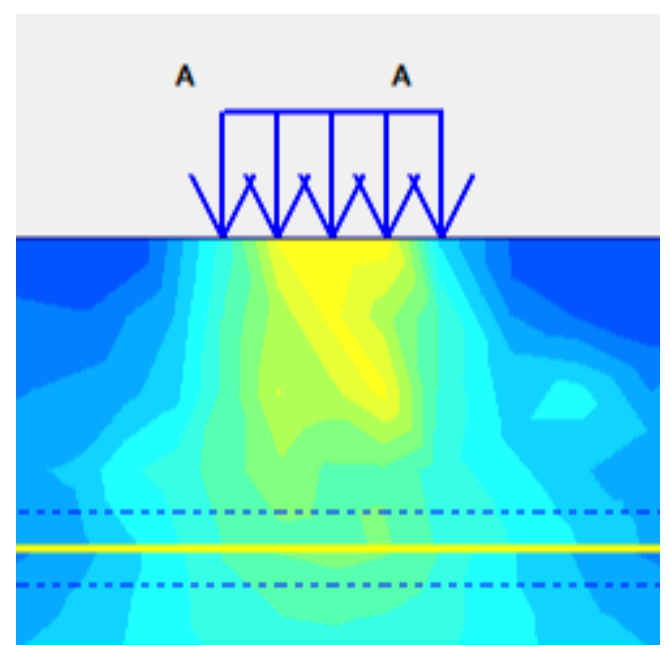

Gambar 5. Distribusi tegangan dengan perkuatan geotekstil

Besarnya distribusi tegangan yang terjadi pada tanah dengan perkuatan geotekstil 0 meter di atas tanah terbagi menjadi beberapa data. Data tersebut dapat dilihat pada Tabel 3.

Tabel 3. Nilai distribusi tegangan dengan perkuatan geotekstil

\begin{tabular}{cc}
\hline $\mathrm{X}(\mathrm{m})$ & $\begin{array}{c}p \\
\left(\mathrm{kN} / \mathrm{m}^{2}\right)\end{array}$ \\
\hline 2,00 & $-6,15$ \\
2,17 & $-16,71$ \\
2,33 & $-25,91$ \\
2,33 & $-26,18$ \\
2,33 & $-26,23$ \\
2,33 & $-27,80$ \\
2,50 & $-32,52$ \\
2,67 & $-28,04$ \\
2,67 & $-25,45$ \\
2,83 & $-15,28$ \\
3,00 & $-7,63$ \\
\hline
\end{tabular}

Pada Tabel 3 nilai terbesar untuk distribusi tegangan adalah sebesar $-32,52 \mathrm{kN} / \mathrm{m}^{2}$. Persen perbandingan untuk perbandingan besarnya nilai teori dan program adalah sebagai berikut:

$$
\begin{aligned}
\% \text { perbandingan } & =\frac{34,3158-32,52}{34,3158} * 100 \\
& =5,2332 \%
\end{aligned}
$$

\section{Efektivitas material geotekstil}

Berikut adalah \%perbandingan dari besarnya nilai distribusi tegangan yang terjadi pada tanah tanpa perkuatan dengan nilai distribusi tegangan yang terjadi pada tanah dengan perkuatan geoteksil:

$$
\begin{aligned}
\% \text { perbandingan } & =\frac{39,42-32,52}{39,42} * 100 \\
& =17,5038 \%
\end{aligned}
$$




$$
\begin{aligned}
\% \text { perbandingan } & =\frac{40,0944-34,3158}{40,0944} * 100 \\
& =14,4125 \%
\end{aligned}
$$

\section{Pengaruh letak geotekstil}

Pada penelitian ini, akan dianalisis pengaruh letak geotekstil terhadap distribusi beban yang terjadi pada tanah dasar. Adapun ringkasan dari pengaruh letak geotekstil dan efektivitasnya dapat dilihat pada Tabel 4.

Tabel 4. Efektivitas penggunaan geotekstil terhadap letaknya

\begin{tabular}{ccc}
\hline $\begin{array}{c}\text { Letak Geotekstil dari Tanah } \\
\text { Dasar }(\mathrm{m})\end{array}$ & $p\left(\mathrm{kN} / \mathrm{m}^{2}\right)$ & $\%$ perbandingan \\
\hline 0 & & 0 \\
0,1 & 32,52 & 22,7552 \\
0,2 & 25,12 & 42,0357 \\
0,3 & 18,85 & 37,8844 \\
0,4 & 20,20 & 28,198 \\
\hline
\end{tabular}

\section{KESIMPULAN DAN SARAN}

\section{Kesimpulan}

Berdasarkan kajian teknis, analisis dan pembahasan yang dilakukan untuk menganalisa pengaruh geotekstil dalam distribusi beban kerja, dapat disimpulkan bahwa:

1. Kondisi tanah yang digunakan baik dalam teori maupun program adalah sebagai berikut:

$$
\begin{array}{ll}
0-4 \mathrm{~m} & : \text { Tanah Gambut (Lanau Organik) } \\
4-12 \mathrm{~m} & : \text { Pasir Lanauan } \\
12-20 \mathrm{~m} & \text { : Lanau Pasiran }
\end{array}
$$

Untuk keperluan perhitungan hanya digunakan tanah lapisan $0-4$ meter saja yang merupakan tanah sangat lunak sebagai acuan tanah dasar untuk jalan Unpaved Road.

2. Tinggi timbunan diasumsikan sama baik untuk teori maupun perhitungan dengan program yakni sebesar 0,5 meter.

3. Untuk besarnya nilai distribusi tegangan terjadi pada tanah tanpa perkuatan geotekstil adalah sebesar 40,0944 $\mathrm{kN} / \mathrm{m}^{2}$ secara teori dan $39,42 \mathrm{kN} / \mathrm{m}^{2}$ dengan program, dengan perkuatan geotekstil adalah sebesar 34,3158 $\mathrm{kN} / \mathrm{m}^{2}$ secara teori dan $32,52 \mathrm{kN} / \mathrm{m}^{2}$ dengan program.

4. Geotekstil sangat membantu dalam mengurangi distribusi tegangan yang terjadi pada tanah, dimana distribusi tegangan pada tanah mengecil dan besarnya distribusi tegangan yang terjadi juga berkurang.

5. Letak geotekstil yang paling efektif digunakan pada studi ini adalah pada 0,2 meter diatas timbunan, dimana menghasilkan nilai distribusi tegangan paling kecil pada tanah dasar yaitu sebesar $18,85 \mathrm{kN} / \mathrm{m}^{2}$.

6. Efektivitas dari penggunaan material geosintetik adalah sebesar 17,5038\% secara program dan $14,4125 \%$ secara teori.

\section{Saran}

Dari hasil analisis yang telah dilakukan, penulis memberikan beberapa saran untuk melengkapi kekurangankekurangan yang ada, antara lain:

1. Melakukan perbandingan dengan keadaan secara real dalam penggunaan geosintetik pada jalan Unpaved Road dengan tinggi timbunan 0,5 meter.

2. Melakukan uji laboratorium untuk mendapatkan data yang lebih akurat, dan menambahkan titik area yang ditinjau. 
3. Melakukan analisis untuk berbagai jenis tinggi timbunan yang berbeda.

4. Melakukan analisis dengan menggunakan jenis material geosintetik yang berbeda dan kuat tarik yang berbeda.

5. Melakukan analisis dengan mengganti jenis tanah dasar yang akan digunakan, seperti misalnya jenis tanah keras atau tanah medium.

6. Melakukan analisis dengan mengganti tinggi timbunan yang digunakan.

\section{DAFTAR PUSTAKA}

Budhu, Muni. Soil Mechanics and Foundation. 3rd Edition, New Jersey: John Wiley \& Sons, Inc, 2011.

Giroud, J.P dan Noiray. "Design of Geotextile Reinforced Unpaved Roads". Journal of the Geotechnical Engineering Division, vol. 107, no. 9, 1981, pp. 1233-1254.

Departemen Pekerjaan Umum. Pedoman Konstruksi dan Bangunan: Perencanaan Dan Pelaksanaan Perkuatan Tanah Dengan Geosintetik, Departemen Pekerjaan Umum, 2009.

John, N.W.M. Geotextiles. New York: Blackie Chatman and Hall, 1987.

Vipulanandan, C. dan O Bilgin. Prediction of Embankment Settlement Over Soft Soils, Texas Department of Transportation Research and Technology Implementation Office, 2009.

Vargas, P.A.V. ASTM D 4439-00 Standard Terminology for Geosynthethics. American Society for Testing and Materials, 2017. 